\title{
RISKS OF ORAL METHOTREXATE ADMINISTRATION IN OUTPATIENTS
}

\author{
Maria G. Ganeva, \\ Tanya T. Gancheva ${ }^{1}$, \\ Ivan D. Baldaranov, \\ Nataliya J. Kiriyak', \\ Evgeniya H. Hristakieva ${ }^{1}$
}

Section of Pharmacology and Clinical Pharmacology

${ }^{1}$ Clinic of Dermatology and Venereology, University Hospital Faculty of Medicine Thracian University Stara Zagora

Corresponding Author:

Maria G. Ganeva

e-mail: mariaganeva@hotmail.com

Received: October 03, 2014

Revision received: November 11, 2014 Accepted: November 24. 2014

\begin{abstract}
Summary
Methotrexate (MTX) is a cytostatic agent used in oncology. Because of its immunosuppressive properties, MTX is also used in autoimmune disorders. Low-dose MTX regimens in the treatment of rheumatoid arthritis and severe psoriasis are considered to be safe. However, pharmacovigilance centers warn of serious and even fatal incidents due to errors in oral MTX administration. The aim of this case series presentation was to identify the specific factors related to the development of adverse drug reactions (ADRs) induced by MTX. A prospective pharmacovigilance study was conducted at the Clinic of Dermatology, University Hospital, Stara Zagora. We report 3 cases of patients with psoriasis vulgaris in which severe haematological abnormalities associated with previous administration of MTX were detected during hospitalization. A 73-year old female with malaise, vomiting and oral ulcers who had taken approximately $120 \mathrm{mg}$ MTX was found to have pancytopenia. A 59-year old male hospitalized for psoriatic erythroderma who had erroneously taken $10 \mathrm{mg}$ MTX daily instead of weekly for 8 days, was diagnosed with bicytopenia and toxic hepatitis. An 88-year old male with psoriatic arthritis presented with aphthous stomatitis, erosive crusted lesions, ecchymoses and aplastic anemia 2 weeks after treatment with $12.5 \mathrm{mg}$ MTX once weekly plus i.m. Movalis ${ }^{\circledR}$, followed by Diclophenac Duo ${ }^{\circledR}$. The main predisposing factors for the development of these ADRs were patient-related dosage errors and concomitant administration of NSAIDs. Safe use of oral MTX requires clear dosing instructions and strict patient compliance. Potential drug interactions of MTX with other drugs should also be considered.
\end{abstract}

Key words: methotrexate, adverse drug reactions, pancytopenia

\section{Introduction}

Methotrexate (MTX) has been used since the 1940s as an antitumor agent. MTX is a folic acid antagonist that binds to dihydrofolate reductase and blocks the synthesis of tetrahydrofolic acid and purine and pyrimidine precursors of DNA and RNA required for cell proliferation. In 1951, MTX was introduced for the treatment of rheumatoid arthritis (RA) because of its property to inhibit the proliferation of 
lymphocytes and other cells participating in joint inflammation [1]. At the comparatively low doses used in rheumatic diseases MTX exhibits anti-inflammatory activity [2] and this is probably related to the inhibition of the folatedependent enzyme 5-aminoimidazole-4carboxamide ribonucleotide (AICAR) transformilase [3] and the consequent inhibition of the key enzymes adenosine deaminase and AMP deaminase, resulting in the intracellular increase of adenosine and adenine nucleotides [4]. Extracellular adenosine can bind to several subtypes of transmembrane receptors $\left(A_{1}, A_{2 a}\right.$, $A_{2 b}, A_{3}$ ) found on many cell types. It is speculated that low-dose MTX exerts its anti-inflammatory activity by increasing extracellular adenosine which activates predominantly $\mathrm{A}_{2 \mathrm{a}}$ and $\mathrm{A}_{3}$ adenosine receptors leading to inhibition of lymphocyte proliferation and the production of proinflammatory interleukins and leucotrienes $[6,7]$. Clarifying MTX anti-inflammatory and immunosuppressive mechanism is important for the search of biomarkers that could be helpful in a preliminary identification of patients who would respond to MTX treatment or are prone to develop toxicities to MTX. At present no reliable markers are available. The study of some promising candidates such as erythrocyte levels of the active MTX metabolite MTXpolyglutamate, polymorphisms of genes encoding purine and pyrimidine synthesis, etc. continues [7].

In Bulgaria MTX is approved for the treatment of oncological (solid tumors and haematologic malignancies) and nononcological diseases (active rheumatoid arthritis in adults and severe psoriasis in patients nonresponsive to other treatments). MTX is a disease-modifying antirheumatic drug (DMARD) that should be part of the first treatment strategy in patients with active rheumatoid arthritis according to recent European League against Rheumatism (EULAR) guidelines [8]. MTX is recommended as a first choice DMARD for psoriatic arthritis [9]. MTX is considered to be an effective, safe and cheap medicine [10-13].

The MTX summary of product characteristics recommends assessment of haematological parameters, renal and hepatic function before treatment. Routine baseline investigations include full blood count, chest X-ray, and renal and hepatic functional tests. During treatment full blood counts should be monitored at least once a month and hepatic and renal function once monthly or every 3 months. In oncology more frequent monitoring is recommended. Mild adverse drug reactions (ADRs) like stomatitis, nausea, vomiting, diarrhoea are observed in 20 to $30 \%$ of the patients treated with MTX. Severe ADRs present as hepatic, renal, pulmonary impairments. Bone marrow is rarely affected. Risk factors include high MTX dosage, old age, kidney diseases, hypoalbuminemia, folic acid deficiency, infections, and drug interactions.

Three cases of serious MTX-induced ADRs were detected in the course of a pharmacovigilance study in the Clinic of Dermatology, University Hospital, Stara Zagora.

\section{Clinical case $\mathrm{No1}$}

D.K., an 88 -year-old male with a 20 -year history of psoriasis was admitted to hospital with painful erosions affecting the mouth, face, upper and lower limbs of 3day's duration. Two weeks before hospitalization treatment for psoriatic arthritis was started. The treatment schedule included peroral MTX $12.5 \mathrm{mg}$ once weekly plus folic acid combined with meloxicam (Movalis ${ }^{\circledR}$ ) $15 \mathrm{mg}$ i.m. for 5 days followed by peroral diclofenac (Diclofenac-Duo ${ }^{\circledR}$ ) in a dosage of $75 \mathrm{mg}$ daily for 8 days. Concomitant diseases were arterial hypertension, deafness, and prostatic hyperplasia. On admission the patient was afebrile, his tongue was covered with a whitish coating, and so were the erosions on the palate and buccal mucosa. Erosive-crusted lesions with oval and irregular shape ranging from 1 to $10-15$ $\mathrm{cm}$ in diameter were present on his face, scalp, forearms, elbows and lower legs (Figure 1).

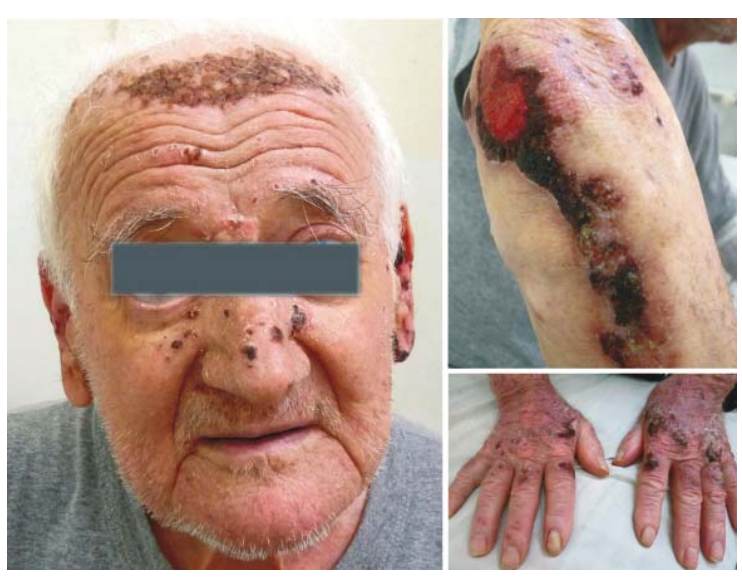

Figure 1. Erosive crusted lesions on the face, elbow and back of hands 
Most of the erosions were covered with yellowbrownish crusts. Single ecchymoses were seen on the dorsal aspects of the feet. Laboratory analysis revealed an elevated erythrocyte sedimentation rate (ESR) 46/80 mm, white blood cell count of $0.74 \times 10^{9} / \mathrm{L}$, hemoglobin $106 \mathrm{~g} / \mathrm{L}$, erythrocytes $3.4 \times 10^{12} / \mathrm{L}$, platelets $33 \times 10^{9} / \mathrm{L}$, total protein $57.6 \mathrm{~g} / \mathrm{L}$, albumin $28.07 \mathrm{~g} / \mathrm{L}$, glucose $6.95 \mathrm{mmol} / \mathrm{L}$, urea $19.78 \mathrm{mmol} / \mathrm{L}$. Creatinine and aminotransferases were within normal ranges. Cultures of deposits from the tongue revealed Staphylococcus epidermidis and methicillinsensitive Staphylococcus aureus in skin lesions. After consultation with a hematologist, treatment consisting of filgrastim $\left(\right.$ Neupogen $\left.{ }^{\circledR}\right) 300 \mathrm{mcg}$ s.c. and methylprednisolone (Urbason ${ }^{\circledR} 60 \mathrm{mg}$ i.v. twice daily) for Methotrexate-induced aplastic anemia was started. Anti-infective drugs including amoxicillin-clavulanic acid $\left(\right.$ Augmentin $\left.^{\circledR}\right) 2 \times 1.0$ p.o., ceftriaxone $\left(\right.$ Medaxone $\left.^{\circledR}\right) 2$ x 1.0 i.v., metronidazole (Flagyl ${ }^{\circledR}$ ) $2 \times 0.5$ i.v., and fluconazole (Fungolon ${ }^{\mathbb{B}}$ ) $0.1 / 24 \mathrm{hrs}$ p.o. were used for prophylaxis of bacterial and fungal infections. For prophylaxis of corticosteroid-induced gastrointestinal ADRs, esomeprazole (Emanera $\left.{ }^{\circledR}\right) 2$ × $20 \mathrm{mg}$ p.o. was administered. Concomitant diseases were treated with Co-Linipril ${ }^{\circledR}$, Isodinit ${ }^{\circledR}$, and Zoxon ${ }^{\circledR}$. Topical therapy consisted of linimentum cum Chlorocid, fusidic acid $\left(\right.$ Fucidin $\left.^{\circledR}\right)$ cream and chlorhexidineimpregnated antiseptic dressings (Bactigras ${ }^{\circledR}$ ). Mouth lesions were treated with topical antiseptics and antifungals - benzydamin (Tantum verde ${ }^{\circledR}$ ), miconazole $\left(\right.$ Daktarin $^{\circledR}$ ) oral gel.Fig.1The patient was transferred to a hematological unit for further treatment of aplastic anemia.

\section{Clinical case $\mathrm{No2}$}

Z.O. a 73-year-old female with a 7-year history of arthropathic psoriasis and concomitant ischaemic heart disease, arterial hypertension, gr. II and NYHA gr. III heart failure was admitted to hospital for severe psoriasis. The patient had been on MTX $5 \mathrm{mg}$ weekly for 1 year and had stopped the drug for a few months due to remission. Because of itchy red lesions in the folds 2 weeks prior to hospitalization the patient took, on her own account, a high dosage of MTX - approximately $120 \mathrm{mg}$ p.o. which resulted in malaise, vomiting and formation of mouth ulcers. On admission the patient was underweight and in poor general condition but afebrile. Extensive erythematous-tohyperpigmented non-infiltrated plaques were found in the inguinal and submammary areas with oozing, whitish coating in the folds and single erosions and hemorrhagic crusts. Buccal mucosa was covered with extensive painful erosions.

Laboratory analysis showed an elevated ESR $90 / 110$, white blood cell count of $2.9 \times 10^{9} / \mathrm{L}$, hemoglobin $109 \mathrm{~g} / \mathrm{L}$, erythrocytes $3.6 \times 10^{12} / \mathrm{L}$, platelets $110 \times 10^{9} / \mathrm{L}$. Glucose, liver and renal tests were within normal ranges. Cultures from skin lesions revealed methicillin-sensitive Staphylococcus aureus and Candida spp. The consulting hematologist confirmed the diagnosis of pancytopenia following MTX treatment and therapy with folic acid in a daily dose of $45 \mathrm{mg}$ and prophylactic administration of antibiotics and antifungals (Amoxiclav ${ }^{\circledR} 3 \times 625 \mathrm{mg}$ plus Fungolon $^{\circledR} 100 \mathrm{mg} / 24 \mathrm{hrs}$ ) was started. Topical therapy consisted of Dermazin ${ }^{\circledR}$ cream, cold cream and benzydamin (Tantum verde ${ }^{\circledR}$ ) mouthwash and $1 \%$ hydrogen peroxide solution for the mouth lesions.

For 10 days full recovery of the mouth and skin lesions was achieved. Hematology parameters showed significant improvement (white blood cell count $6.3 \times 10^{9} / \mathrm{L}$, hemoglobin $114 \mathrm{~g} / \mathrm{L}$, erythrocytes $3.71 \times 10^{12} / \mathrm{L}$, platelets $\left.637 \times 10^{9} / \mathrm{L}\right)$.

\section{Clinical case $\mathrm{No} 3$}

D.I., a 59-year-old male with a long history of psoriasis and alcohol abuse was hospitalized for psoriatic erythroderma. He had erroneously taken $10 \mathrm{mg}$ MTX daily for 8 to 9 days prior to hospitalization. MTX had been prescribed by a dermatologist in a standard once weekly dosage regimen after performing laboratory analysis of complete blood count and clinical biochemistry. After 2-3 days of daily MTX intake the patient was with loss of appetite, malaise and skin erosions. The psoriatic lesions acquired a bluishbrownish shade. Gradually his condition deteriorated, there were symptoms of nausea, vomiting, night chills and the color of urine became dark. On admission he was febrile $\left(38^{\circ}\right.$ C), with blood pressure $140 / 70 \mathrm{~mm} \mathrm{Hg}$, and presented with generalized plaque psoriasis of polycyclic, infiltrated brownish-livid lesions with pityroid desquamation, brownish hemorrhagic crusts and single fresh erosions 
predominantly in the inguinal folds. Erosions and squamous-crusted lesions were found on the face, there was diffuse palmar hyperkeratosis. Laboratory analysis showed elevated ESR $100 / 110$, white blood cell count of $1.8 \times 10^{9} / \mathrm{L}$, hemoglobin $114 \mathrm{~g} / \mathrm{L}$, erythrocytes $3.75 \times 10^{12} / \mathrm{L}$, platelets $16 \times 10^{9} / \mathrm{L}$. Differential blood count was: St 7, Sg 37, Eo 13, Ly 42, Mo1. Fibrinogen was $5.26 \mathrm{~g} / \mathrm{L}$. Glucose, urea, creatinine, uric acid, total protein, prothrombin time and electrolytes were within reference ranges. Liver function tests showed the following: aspartate aminotransferase (AST) $56 \mathrm{U} / \mathrm{L}$; alanine aminotransferase (ALT) 55 U/L; GGTP 299.8 $\mathrm{U} / \mathrm{L}$; alkaline phosphatase (AP) $153.5 \mathrm{U} / \mathrm{L}$; direct bilirubin $77.2 \mu \mathrm{mol} / \mathrm{L}$; total bilirubin 107.7 $\mu \mathrm{mol} / \mathrm{L}$; creatine kinase (CK) $175 \mathrm{U} / \mathrm{L}$; CK-MB 57.6 U/L. Urine was positive for bilirubin and protein, and urobilinogen was significantly elevated.

Urine cultures, cultures from lesional skin and throat swab all yielded Staphylococcus aureus. Hemocultures were negative for bacteria. Antistreptolysin titre was below 250 units. Chest radiography was normal. Abdominal sonography showed hepatomegaly with non-specific diffuse parenchymal changes consistent with toxic hepatitis. Following consultations with a gastroenterologist, a hematologist and a toxicologist the patient was diagnosed with toxic hepatitis and bicytopenia and was treated with folic acid, levulose transfusions, hepatoprotective agents ademetionine and silymarin (Transmetil ${ }^{\circledR} 2$ x 0.5 i.v., Carsil $^{\circledR}$ p.o.), antiinfectious agents (Cefazolin 2.0/8 hrs i.v.) and antipyretics. Topical medication included linimentum cum Chlorocid, Jodasept ${ }^{\circledR}$ ointment and Nystatin ${ }^{\circledR}$ cream. During the hospital stay significant clinical improvement was achieved, liver function normalized with direct bilirubin decreasing to $21.2 \mu \mathrm{mol} / \mathrm{L}$, total bilirubin 27.6 $\mu \mathrm{mol} / \mathrm{L}$, AST $50.9 \mathrm{U} / 1$, ALT $45.9 \mathrm{U} / 1$, hematology parameters revealed increased white blood cell count $\left(5.4 \times 10^{9} / \mathrm{L}\right)$ and platelets $\left(85 \times 10^{9} / \mathrm{L}\right)$ at hospital discharge.

\section{Discussion}

In patients with RA who take MTX in relatively low doses the incidence rate of haematologic ADRs like leucopenia, thrombocytopenia, megaloblastic anemia and pancytopenia is estimated to be 3\% [14]. A study of a series of patients with pancytopenia induced by MTX administered in a median weekly dose of $12.5 \mathrm{mg}$ has shown that it is very important to monitor patients for haematologic ADRs for a long period of time because these ADRs may appear late in the course of therapy with MTX [15]. Although therapy of RA with MTX is considered to be safe, vigilance concerning ADRs should not be ignored. Precipitating factors for MTX toxicity are poor nutritional status, hypoalbuminemia, renal impairment [15]. Nevertheless, bone marrow suppression in patients on low-dose MTX with no clear risk factors has been reported [16]. Folic acid supplementation in a dose of $5 \mathrm{mg}$ weekly in patients taking MTX may reduce the incidence of bone marrow suppression [16].

In the first reported case MTX had been prescribed without preliminary laboratory investigations. The role of combined therapy with nonsteroidal anti-inflammatory drugs (NSAIDs) i.e. meloxicam and diclofenac for the development of MTX-induced ADRs cannot be ruled out. The drug interaction between MTX and NSAIDs is pharmacokinetic - MTX excretion is reduced by NSAIDs resulting in elevation of MTX plasma levels and consequently increasing the risk of MTX toxicity. It is not recommended to combine high doses of MTX (above $15 \mathrm{mg}$ weekly) with NSAIDs. Even if low MTX doses are used in combination with NSAIDs, the risk of haematologic toxicity of MTX might increase despite of the unchanged MTX pharmacokinetics. Short-term studies show lack of pharmacokinetic interaction of meloxicam with MTX in patients with rheumatoid arthritis [17] and no difference in the safety profile of the drug when administered with meloxicam [18]. Although adverse pharmacokinetic interactions with MTX are reported for ketoprofen, indomethacin, naproxen, diclofenac [19], for aspirin, ibuprofen, etodolac [20], and despite the lack of ADRs in most patients on combined therapy, it is recommended that all patients on MTX combined with any NSAID be cautiously monitored [20].

In the second and third case, MTX toxicity can be attributed to the patients' self willing increase in the dose of MTX. Errors in oral MTX administration are related to specific weekly MTX administration regimen in RA and psoriasis. MTX overdose due to daily instead of weekly administration is not uncommon [21-23]. Analysis of adverse events to MTX due to its erroneous administration reported to the FDA for a 4-year period show that in $20 \%$ of the cases errors are patient-related and in $37 \%$ errors are 
physician-related [24]. Medical journals and drug regulatory authorities from all over the world warn of inadvertent daily prescribing, dispensing or administering of MTX resulting in serious ADRs including death [25-27].

Another factor contributing to MTX hepatotoxicity in case 3 is the history of excessive alcohol consumption. Long-term use of MTX in low weekly doses can cause liver fibrosis and cirrhosis [28]. The risk of liver toxicity is increased by previous or current alcohol use. MTX is not considered to be suitable for patients suspected of alcohol abuse [29].

\section{Conclusions}

Safe administration of oral MTX is based on strict adherence to the dosage regimen instructions and monitoring of patients by their attending doctor or general practitioner. Clear and understandable information on the dosing schedule of MTX received by the patients and available in all medical documentation (prescription, personal health records, drug package) is necessary to prevent errors in oral MTX administration. Individual patient compliance with drug treatment recommendations should also be carefully evaluated.

\section{Acknowledgements}

The present work is supported by grant $15 / 2013$, Faculty of Medicine, Thracian University, Stara Zagora.

\section{References}

1. Gubner R, August S, Ginsberg V. Therapeutic suppression of tissue reactivity. II. Effect of aminopterin in rheumatoid arthritis and psoriasis. Am J Med Sci. 1951;221(2):176-82.

2. Kremer JM. The mechanisms of action of methotrexate in rheumatoid arthritis: the search continues. J Rheumatol. 1994;21(1):1-5.

3. Furst DE, Ulrich RW. Nonsteroidal antiinflammatory drugs, disease-modifying antirheumatic drugs, nonopioid analgesics, \& drugs used in gout. In: Katzung BG, editor. Basic \& Clinical Pharmacology. McGraw-Hill Medical Publishing; 2007. p. 573-99.
4. Baggott JE, Vaughn WH, Hudson BB. Inhibition of 5-aminoimidazole-4-carboxamide ribotide tranformylase, adenosine-deaminase and 5adenylate deaminase by polyglytamates of methotrexate and oxidized folates and by 5aminoimidazole-4-carboxamide riboside and ribotide. Biochem J. 1986;236:193-200.

5. Cutolo M, Sulli A, Pizzorni C, Seriolo B. Antiinflammatory mechanisms of methotrexate in rheumatoid arthritis. Ann Rheum Dis. 2001;60(8):729-35.

6. Chan ESL, Cronstein BN. Molecular action of methotrexate in inflammatory diseases. Arthritis Res. 2002;4(4):266-73.

7. Halilova KI, Brown EE, Morgan SL, Bridges SL, Hwang MH, Arnett DK, Danilla MI. Markers of treatment response to methotrexate in rheumatoid arthritis: where do we stand? Int J Rheumatol. 2012;2012:ID978396, 7 pages [cited 2014 Jul 16]. Available from: (http://dx.doi.org/10.1155/2012/978396)

8. Smolen JS, Landewé R, Breedveld FC, Buch M, Burmester $G$, Dougados $M$, et al. EULAR recommendations for the management of rheumatoid arthritis with synthetic and biological disease-modifying antirheumatic drugs: 2013 update. Ann Rheum Dis. 2014;73:492-509.

9. Gossec L, Smolen JS, Gaujoux-Viala C, Ash Z, Marzo-Ortega H, van der Heijde D et al. European League Against Rheumatism. European League Against Rheumatism recommendations for the management of psoriatic arthritis with pharmacological therapies. Ann Rheum Dis. 2012;71(1):4-12.

10. Papadopoulos NG, Alamanos Y, Papadopoulos IA, Tsifetaki N, Voulgari PV, Drosos AA. Disease modifying antirheumatic drugs in early rheumatoid arthritis: a longterm observational study. J Rheumatol. 2002;29(2):261-6.

11. Yazici Y, Sokka T, Kautiainen H, Swearingen C, Kulman I, Pincus T. Long-term safety of methotrexate in routine clinical care: Discontinuation is unusual and rarely due to laboratory abnormalities. Ann Rheum Dis. 2005;64(2):207-11.

12. Yazici Y, Erkan D, Harrison MJ, Nikolov NP, Paget SA. Methotrexate use in rheumatoid arthritis is associated with few clinically significant liver function test abnormalities. Clin Exp Rheumatol. 2005;23(4):517-20.

13. Yazici Y. Long-term safety of methotrexate in the treatment of rheumatoid arthritis. Clin Exp Rheumatol. 2010;28(5 Suppl 61):S65-7.

14. Weinblatt ME. Toxicity of low dose methotrexate in rheumatoid arthritis. J Rheumatol. 1985;(Suppl 12):35-9.

15. Lim AYN, Gaffney K, Scott DGI. Methotrexateinduced pancytopenia: serious and underreported? Our experience of 25 cases in 5 years. Rheumatol. 2005;44(8):1051-5. 
16. Hübner G, Sander O, Degner FL, Türck D, Rau R. Lack of pharmacokinetic interaction of meloxicam with methotrexate in patients with rheumatoid arthritis. Rheumatol. 1997;24(5):845-51.

17. Sosin M, Handa S. Low dose methotrexate and bone marrow suppression. BMJ. 2003;326(7383):266-7.

18. Xie RL, Li XH, Kang XT. Methotrexate in conjunction with meloxicam for treating ankylosing spondylitis: a clinical observation of the efficacy and safety. Di Yi Jun Yi Da Xue Xue Bao. 2003;23(5):460-2.

19. Patanè $M$, Ciriaco M, Chimirri S, Ursini F, Naty S, Grembiale RD et al. Interactions among low dose of methotrexate and drugs used in the treatment of rheumatoid arthritis. Adv Pharmacol Sci. 2013 May 12;2013:313858, [cited 2014 Jul 16]. Available from:

http://www.ncbi.nlm.nih.gov/pmc/articles/PMC3 667469/

20. Baxter K, editor. Antineoplastics. In: Stockley's Drug Interactions: a source book of interactions, their mechanisms, clinical importance and management. 9th ed. London: Pharmaceutical Press; 2010. p.752-4.

21. Bookstaver PB, Norris L, Rudisill C, DeWitt T, Aziz S, Fant J. Multiple toxic effects of low-dose methotrexate in a patient treated for psoriasis. Am J Health Syst Pharm. 2008;65(22):2117-21.

22. Kelly K, Vaida AJ. Beware of erroneous daily oral methotrexate dosing! Pharmacy Times. Medication Safety. 2005 Febr 1 [cited 2014 Jul 16]. Available from:

http://www.pharmacytimes.com/publications/iss ue/2005/2005-02/2005-02-9297
23. Incidents of inadvertent daily administration of methotrexate. ISMP Can Saf Bull. 2008;8(2):1-2.

24. Moore TJ, Walsh CS, Cohen MR. Reported medication errors associated with methotrexate. Am J Health Syst Pharm. 2004;61(13): 380-4.

25. Adverse Drug Reactions Advisory Committee of the Australian Drug Evaluation Committee. Methotrexate-name the day. Aust Adv Drug React Bull. 1998 May [cited 2014 Jul 16];17(2):3. Available from: http://www.tga.gov.au/hp/aadrb9805.htm\#.U8ZBCEDa1kg

26. ISMP.org [Internet]. Huntingdon (PA): Institute for Safe Medication Practices. Special alert. Methotrexate overdose due to inadvertent administration daily instead of weekly. 2002 Dec 3. [cited 2014 Jul 16] Available from: http://www.ismp.org/hazardalerts/ha.pdf

27. bpac.org.nz [Internet]. Methotrexate prescribing errors can be fatal. BPJ. 2011 Febr [cited 2014 Jul 16]. Available from:

http://www.bpac.org.nz/BPJ/2011/february/meth otrexate.aspx

28. West SG. Methotrexate hepatotoxicity. Rheum Dis Clin North Am. 1997;23(4):883-915.

29. Chakravarty K, McDonald H, Pullar T, Taggart A, Chalmers R, Oliver S, et al.; British Society for Rheumatology, British Health Professionals in Rheumatology Standards, Guidelines and Audit Working Group in consultation with the British Association of Dermatologists. BSR/BHPR guideline for disease-modifying anti-rheumatic drug (DMARD) therapy in consultation with the British Association of Dermatologists. Rheum. 2008; 47(6):924-5. 